\title{
Hypocalcemia in a Patient With Metastatic Prostate Cancer From Denosumab Treatment
}

\author{
Sugam Gouli ${ }^{1}$, Jimmy Wang ${ }^{1}$, Anush Patel ${ }^{2}$, Jeffery Allerton ${ }^{2}$ \\ 1. Internal Medicine, Bassett Medical Center, Cooperstown, USA 2. Hematology / Oncology, Bassett Medical Center, \\ Cooperstown, USA
}

Corresponding author: Sugam Gouli, goulisugam@gmail.com

\begin{abstract}
Denosumab is a humanized monoclonal antibody that binds RANKL to inhibit osteoclast activity. It is indicated for the prevention of skeletal-related events (SRE) in patients with solid tumors who have bone metastasis and in patients with multiple myeloma. Hypocalcemia is one of the known side effects of denosumab, which can be prevented with calcium supplementation.

We present a case of a 72-year-old male with diagnosed metastatic prostate cancer who had received one dose of denosumab 10 days prior to presentation with fatigue, insomnia, and somnolence. His labs showed severe (Grade 4) hypocalcemia, which improved with intravenous calcium supplementation. This case highlights a known but life-threatening side effect of denosumab and the potential need for prolonged calcium monitoring in patients placed on the drug.
\end{abstract}

Categories: Endocrinology/Diabetes/Metabolism, Oncology

Keywords: hypocalcemia, denosumab, prostate cancer, sre, super scan

\section{Introduction}

Denosumab is a human monoclonal antibody that acts by inhibiting the receptor activator of nuclear factor$\mathrm{kB}$ ligand (RANKL) and is commonly used to prevent skeletal-related events (SRE) in patients with metastatic solid tumors and multiple myeloma. Denosumab has been proven to be more effective than zoledronic acid in preventing skeletal-related events in patients with metastatic prostate

cancer. Hypocalcemia is one of the side effects of denosumab, which can also be seen in metastatic prostate cancer. Although often mild and transient, hypocalcemia can lead to significant morbidity or even mortality. Careful monitoring of calcium levels is required in patients with metastatic prostate cancer getting denosumab.

Review began 07/25/2021 Review ended 08/04/2021 Published 08/10/2021

\section{๑) Copyright 2021}

Gouli et al. This is an open access article distributed under the terms of the Creative Commons Attribution License CC-BY 4.0., which permits unrestricted use, distribution, and reproduction in any medium, provided the original author and source are credited.

\section{Case Presentation}

A 72-year-old male who was recently diagnosed with metastatic prostate cancer presented with fatigue, insomnia with daytime somnolence. The patient's metastatic prostate cancer was Gleason score $(5+5=10)$ with extensive bone metastasis. His bone scan was described as a "super scan" (Figure 1) due to the intense and extensive radiopharmaceutical uptake. He received one dose of denosumab and leuprolide/docetaxel 10 days prior to his admission. Upon physical examination, he appeared fatigued but still alert and oriented. Neurological examination showed $4 / 5$ strength and decreased reflexes in all four extremities, without Chvostek sign, clonus, or asterixis. His initial laboratory testing showed new hypocalcemia $2.6 \mathrm{mg} / \mathrm{dl}$ ionized (normal range 4.65 to $5.2 \mathrm{mg} / \mathrm{dl}$ ), hypophosphatemia $1.4 \mathrm{mg} / \mathrm{dl}$ (normal range $2.5-4.5 \mathrm{mg} / \mathrm{dl}$ ), and neutropenia absolute neutrophil count (ANC) 790 cell/ul. Parathyroid hormone was elevated at $1140 \mathrm{pg} / \mathrm{ml}$ (normal range 14 to $65 \mathrm{pg} / \mathrm{ml}$ ) and total vitamin D was as low as $13 \mathrm{ng} / \mathrm{ml}$ (normal range 20-40 ng/ml). The patient was started on calcium gluconate infusion ( $13 \mathrm{~g} /$ day), oral calcium carbonate $500 \mathrm{mg}$ twice a day, and oral calcitriol $0.25 \mathrm{mcg}$ daily. Calcium gluconate infusion was stopped after four days as calcium was gradually increasing, and the patient was continued on oral calcium. A few days after the discontinuation of IV calcium, the ionized calcium level gradually decreased to $2.9 \mathrm{mg} / \mathrm{dl}$, necessitating switching oral calcitriol to IV calcitriol $4 \mu \mathrm{g}$ daily for three days with ionized calcium level improving to $4.1 \mathrm{mg} / \mathrm{dl}$. The patient was discharged with oral calcitriol $0.75 \mathrm{mg}$ BID, oral calcium carbonate $2 \mathrm{~g}$ BID, and vitamin D 50,000 Units weekly. Three days after discharge, ionized calcium level was found to be slightly decreased to $3.8 \mathrm{mg} / \mathrm{dl}$ and oral calcium carbonate was increased to $2 \mathrm{~g}$ TID. Ionized calcium was rechecked 10 days after discharge and increased to $4.2 \mathrm{mg} / \mathrm{dl}$ (Figure 2). 


\section{Cureus}
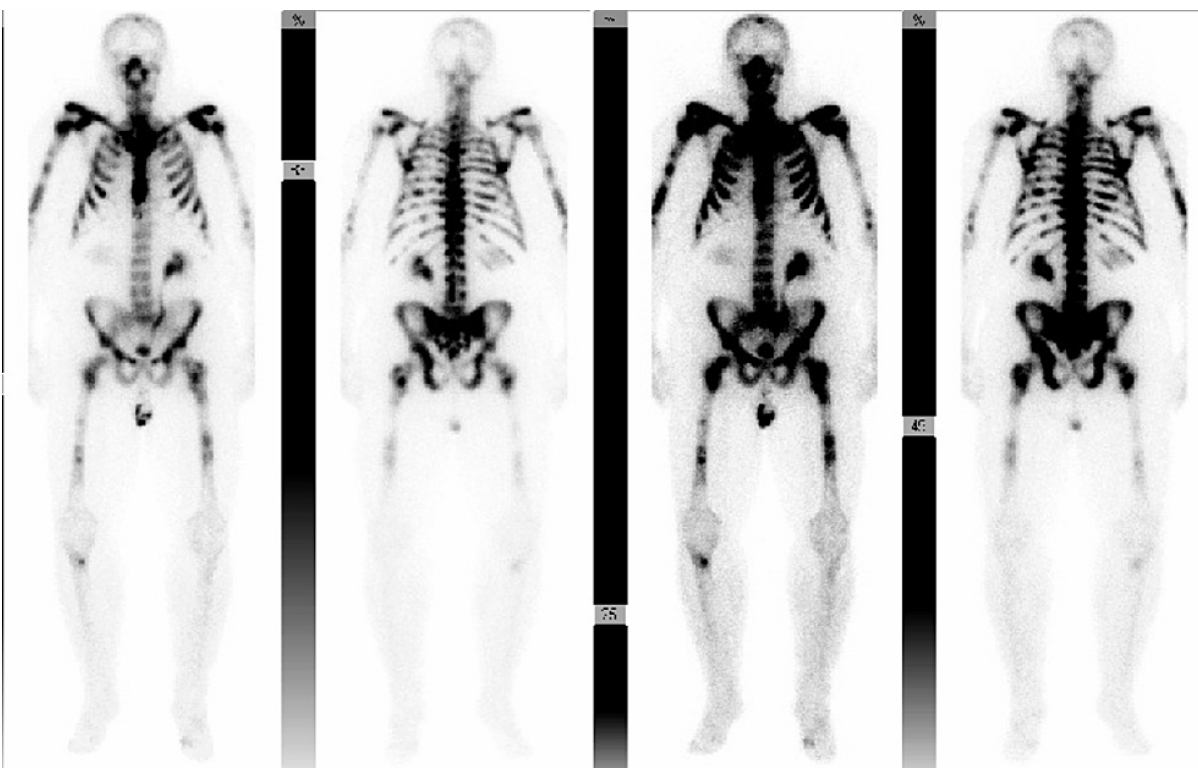

FIGURE 1: Shows "super scan" in technetium-99m (Tc-99m) methylene diphosphonate (MDP) whole body scan scan of the patient

Super scan is a diffusely increased radioisotope uptake in the bones with absent or faint renal and soft tissue activity on a Tc-99m MDP labeled bone scan.

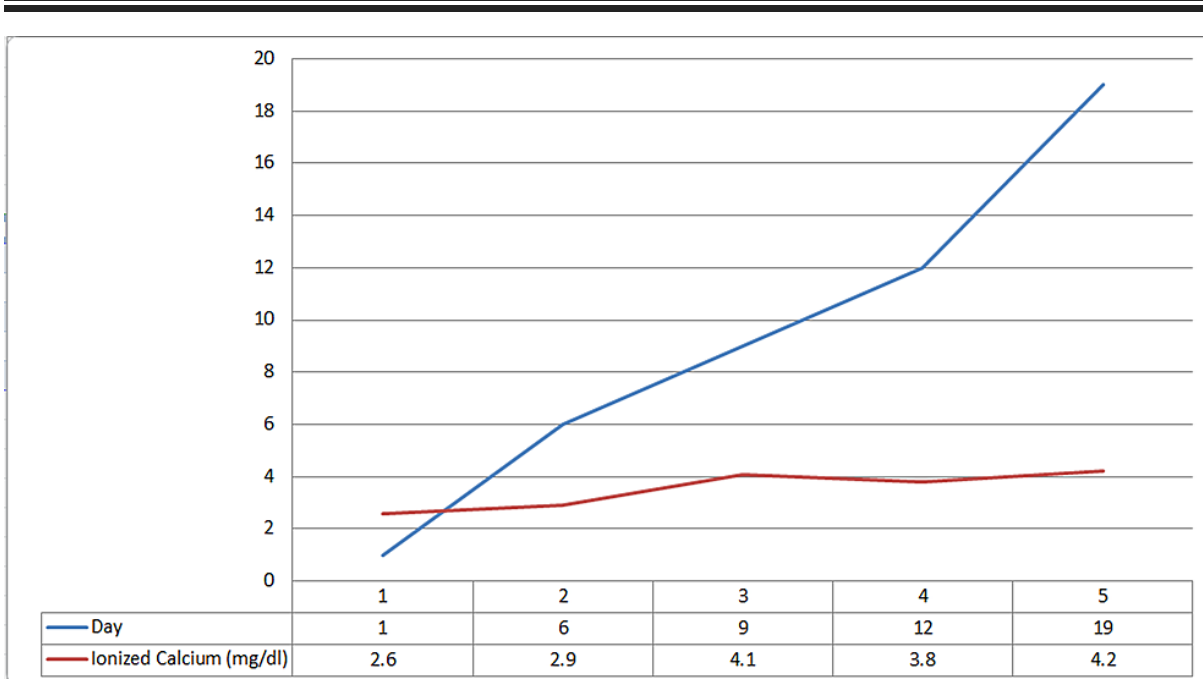

FIGURE 2: lonized calcium level (mg/dl) after calcium supplementation in patients with hypocalcemia

\section{Discussion}

Prostate cancer is the second most common cancer (13.5\% ) in men and among the leading causes of death in men (6.7\%) [1]. Prostate cancer may be asymptomatic at the early stage and generally has an indolent course. However, in a more advanced state, it commonly metastasizes to the bones, leading to complications like pathologic fractures, spinal cord compression, and bone pain, collectively referred to as skeletal-related events [2]. The axial skeleton is the most common site for metastasis [2]. Multiple post-mortem studies in animals and humans have shown venous blood from the breasts and pelvis flowed through the vertebralvenous plexus that extends throughout the epidural and peri-vertebral veins, which partly explains the metastasis of prostate cancer to the axial skeleton [3].

Medications indicated for the prevention of skeletal-related events are anti-resorptive bone-modifying agents like bisphosphonates and denosumab [4]. Denosumab is a human monoclonal antibody used for skeletal-related events (SRE) in postmenopausal women who are at risk of osteoporosis and in patients with bony metastases of solid tumor. Denosumab binds to RANKL and prevents its binding to the RANK receptor; 
thus, limiting excessive bone resorption and decreasing the fracture risk.

The FREEDOM trial showed that denosumab reduced the fracture risk in postmenopausal women by $2.3 \%$ in the denosumab group compared to $7.2 \%$ in the placebo group (CI 0.26 to $0.41 ; \mathrm{P}<0.001$ ) and did not increase the risk of adverse events in patients with glomerular filtration rate (GFR) $>=30$ [5]. It has also shown improved efficacy, better tolerability, and is convenient to administer as compared to bisphosphonates (another group of drugs used to reduce fracture risks) [6].

Our search showed that numerous studies have been conducted to compare denosumab and zoledronic acid regarding their ability to delay skeletal-related events and onset of bone metastasis, as shown in Table 1 .

\begin{tabular}{|c|c|c|}
\hline Column 1 & Column 2 & Column 3 \\
\hline $\begin{array}{l}\text { Type of } \\
\text { study }\end{array}$ & Author & Results \\
\hline RCT & $\begin{array}{l}\text { Lipton et } \\
\text { al. }\end{array}$ & $\begin{array}{l}\text { Delay in first SRE (HR 0.82, Cl 0.71-0.95,p =0.01), median time: unknown in denosumab vs } 26.4 \text { months in } \\
\text { zoledronic acid [7]. }\end{array}$ \\
\hline RCT & Fizazi et al. & $\begin{array}{l}\text { Delay in first SRE (HR 0.82, Cl 0.71-0.95, } \mathrm{p}<=0.01) \text {, median time: } 20.7 \text { months in denosumab vs } 17.1 \\
\text { months in zoledronic acid [8]. }\end{array}$ \\
\hline $\begin{array}{l}\text { meta- } \\
\text { analysis }\end{array}$ & $\begin{array}{l}\text { Chen C et } \\
\text { al. }\end{array}$ & Delay in first SRE (HR = 0.86; 95\% Cl, 0.80-0.93; $\mathrm{P}=0.0001)$, no difference in overall surviva[9]. \\
\hline $\begin{array}{l}\text { meta- } \\
\text { analysis }\end{array}$ & $\begin{array}{l}\text { Zheng G et } \\
\text { al. }\end{array}$ & Delay in first SRE (OR =0.82; 95\% Cl, 0.75-0.89; $\mathrm{P}<0.01$ ), no difference in overall survival[10]. \\
\hline $\begin{array}{l}\text { meta- } \\
\text { analysis }\end{array}$ & $\begin{array}{l}\text { Hayes et } \\
\text { al. }\end{array}$ & Delay onset of bone metastasis in non-metastatic prostate cancer (RR 0.83, Cl 0.73-0.95; P <0.01)[11]. \\
\hline
\end{tabular}

TABLE 1: Studies comparing denosumab vs zoledronic acid

RCT: randomized control trial; SRE: skeletal-related events

Studies have shown that denosumab has a higher risk of hypocalcemia compared to zoledronic acid. Lik-Hui et al. mentioned in their review article that all-grade hypocalcemia in patients was (9.6\%-13\%) in multiple RCTs, (14\%-39.6\%) in observational studies with denosumab [12]. Other studies have shown similar results in a decrease in SRE and increased risk of hypocalcemia [13-14]. Most studies have shown hypocalcemia within a one-week and one-month period [15-17]. Few patients have hypocalcemia of grade 4 ( $<6$ $\mathrm{mg} / \mathrm{dl}$ ) while others have a high incidence of hypocalcemia grades 1-3 [17-18]. This study showed that the incidence of denosumab-associated hypocalcemia was $14 \%$ (95\% CI 9.1-20.7) within six months of treatment despite the use of appropriate calcium/cholecalciferol supplementation [19].

Hypocalcemia itself is also a rare phenomenon in cancer metastasis. Riancho et al. showed that about $75 \%$ of cases of hypocalcemia in cancer metastasis were from prostate cancer metastasis [20]. Prostate cancer metastasis is an osteoblastic, process and the influx of calcium into bone due to increased bone formation causes hypocalcemia [21]. The incidence of denosumab-induced hypocalcemia is high in dialysis patients as shown by this study that found it to be $42 \%$ [22].

Intravenous calcium treatment is required for patients with serum calcium $<7.6 \mathrm{mg} / \mathrm{dl}(1.9 \mathrm{mmol} / \mathrm{L})$ and/or symptomatic hypocalcemia. The guideline suggests $10-20 \mathrm{ml}$ of $10 \%$ calcium gluconate in $50-100 \mathrm{ml}$ of $5 \%$ dextrose intravenous (IV) over 10 min with ECG monitoring and repeating until the patient is asymptomatic. This should be followed up by diluting $100 \mathrm{ml}$ of $10 \%$ calcium gluconate (10 vials) in $1 \mathrm{~L}$ of normal saline or $5 \%$ dextrose and infuse at $50-100 \mathrm{ml} / \mathrm{h}$. The rate of infusion should be titrated to achieve normocalcemia [23]. Also, oral calcium, vitamin D, and calcitriol should be given concurrently. Concurrent hypomagnesemia and hypophosphatemia should be treated as well. In patients on denosumab who took supplements of $>=600 \mathrm{mg}$ calcium and $400 \mathrm{IU}$ vitamin D daily, risks of vertebral facture and hypocalcemia were decreased during three years [24].

\section{Conclusions}


Skeletal-related events like pathologic fractures, spinal cord compression, and bone pain are common in metastatic prostate cancer. Denosumab is a bone-protective agent used for the prevention of SREs in prostate cancer. Denosumab can cause hypocalcemia within one week to one month of its administration and may require hospital admission. Patients receiving denosumab should be on calcium + vitamin D supplementation prior to receiving this agent and maintained on supplementation with dosing adjustments based on laboratory parameters. Hypocalcemia can be treated by intravenous calcium or oral calcium, vitamin D, and calcitriol.

\section{Additional Information \\ Disclosures}

Human subjects: Consent was obtained or waived by all participants in this study. Conflicts of interest: In compliance with the ICMJE uniform disclosure form, all authors declare the following: Payment/services info: All authors have declared that no financial support was received from any organization for the submitted work. Financial relationships: All authors have declared that they have no financial relationships at present or within the previous three years with any organizations that might have an interest in the submitted work. Other relationships: All authors have declared that there are no other relationships or activities that could appear to have influenced the submitted work.

\section{References}

1. Bray F, Ferlay J, Soerjomataram I, Siegel RL, Torre LA, Jemal A: Global cancer statistics 2018: GLOBOCAN estimates of incidence and mortality worldwide for 36 cancers in 185 countries. CA Cancer J Clin. 2018, 68:394-424. 10.3322/caac.21492

2. So A, Chin J, Fleshner N, Saad F: Management of skeletal-related events in patients with advanced prostate cancer and bone metastases: Incorporating new agents into clinical practice. Can Urol Assoc J. 2012, 6:46570 .

3. Batson OV: The role of the vertebral veins in metastatic processes . Ann Intern Med. 1942, 16:38-45. 10.7326/0003-4819-16-1-38

4. Cheung FY: Revisiting the role of bone-modifying agents in the management of metastatic prostate cancer . Asia Pac J Clin Oncol. 2018, 14 Suppl 5:13-5. 10.1111/ajco.13061

5. Cummings SR, San Martin J, McClung MR, et al.: Denosumab for prevention of fractures in postmenopausal women with osteoporosis. N Engl J Med. 2009, 361:756-65. 10.1056/NEJMoa0809493

6. Brown-Glaberman U, Stopeck AT: Role of denosumab in the management of skeletal complications in patients with bone metastases from solid tumors. Biologics. 2012, 6:89-99. 10.2147/BTT.S20677

7. Lipton A, Fizazi K, Stopeck AT, et al.: Superiority of denosumab to zoledronic acid for prevention of skeletal-related events: a combined analysis of 3 pivotal, randomised, phase 3 trials. Eur J Cancer. 2012, 48:3082-92. 10.1016/j.ejca.2012.08.002

8. Fizazi K, Carducci M, Smith M, et al.: Denosumab versus zoledronic acid for treatment of bone metastases in men with castration-resistant prostate cancer: a randomised, double-blind study. Lancet. 2011, 377:813-22. 10.1016/S0140-6736(10)62344-6

9. Chen C, Li R, Yang T, et al.: Denosumab versus zoledronic acid in the prevention of skeletal-related events in vulnerable cancer patients: a meta-analysis of randomized, controlled trials. Clin Ther. 2020, 42:14941507.e1. 10.1016/..clinthera.2020.05.019

10. Zheng GZ, Chang B, Lin FX, et al.: Meta-analysis comparing denosumab and zoledronic acid for treatment of bone metastases in patients with advanced solid tumours. Eur J Cancer Care (Engl). 2017, 26:e12541. 10.1111/ecc.12541

11. Hayes AR, Brungs D, Pavlakis N: Osteoclast inhibitors to prevent bone metastases in men with high-risk, non-metastatic prostate cancer: a systematic review and meta-analysis. PLoS One. 2018, 13:e0191455. 10.1371/journal.pone.0191455

12. Lau LH, Cliff ER, Wong V, et al.: Hypocalcaemia following denosumab in prostate cancer: a clinical review . Clin Endocrinol (Oxf). 2020, 92:495-502. 10.1111/cen.14169

13. Ford JA, Jones R, Elders A, et al.: Denosumab for treatment of bone metastases secondary to solid tumours: systematic review and network meta-analysis. Eur J Cancer. 2013, 49:416-30. 10.1016/j.ejca.2012.07.016

14. Qi WX, Lin F, He AN, Tang LN, Shen Z, Yao Y: Incidence and risk of denosumab-related hypocalcemia in cancer patients: a systematic review and pooled analysis of randomized controlled studies. Curr Med Res Opin. 2013, 29:1067-73. 10.1185/03007995.2013.813840

15. Koguchi D, Satoh T, Tsumura H, et al.: Risk factors for hypocalcemia following treatment with denosumab in patients with bone metastases from prostate cancer. J Clin Trials. 2016, 6:1-7. 10.4172/21670870.1000251

16. Autio KA, Farooki A, Glezerman IG, et al.: Severe hypocalcemia associated with denosumab in metastatic castration-resistant prostate cancer: risk factors and precautions for treating physicians. Clin Genitourin Cancer. 2015, 13:e305-9. 10.1016/j.clgc.2014.11.008

17. Lechner B, DeAngelis C, Jamal N, et al.: The effects of denosumab on calcium profiles in advanced cancer patients with bone metastases. Support Care Cancer. 2014, 22:1765-71. 10.1007/s00520-014-2142-2

18. Yerram P, Kansagra S, Abdelghany O: Incidence of hypocalcemia in patients receiving denosumab for prevention of skeletal-related events in bone metastasis. J Oncol Pharm Pract. 2017, 23:179-84. $10.1177 / 1078155216628325$

19. Huynh AL, Baker ST, Stewardson AJ, Johnson DF: Denosumab-associated hypocalcaemia: incidence, severity and patient characteristics in a tertiary hospital setting. Pharmacoepidemiol Drug Saf. 2016, 25:1274-8. $10.1002 / p d s .4045$

20. Riancho JA, Arjona R, Valle R, Sanz J, González-Macías J: The clinical spectrum of hypocalcaemia associated 


\section{Cureus}

with bone metastases. J Intern Med. 1989, 226:449-52. 10.1111/j.1365-2796.1989.tb01423.x

21. Fokkema MI, De Heide LJ, Van Schelven WD, et al.: Severe hypocalcaemia associated with extensive osteoblastic metastases in a patient with prostate cancer. Neth J Med. 2005, 63:34-7.

22. Thongprayoon C, Acharya P, Acharya C, et al.: Hypocalcemia and bone mineral density changes following denosumab treatment in end-stage renal disease patients: a meta-analysis of observational studies. Osteoporos Int. 2018, 29:1737-45. 10.1007/s00198-018-4533-6

23. Turner J, Gittoes N, Selby P: Society for Endocrinology Endocrine Emergency Guidance: emergency management of acute hypocalcaemia in adult patients. Endocr Connect. 2016, 5:G7-8. 10.1530/EC-16-0056

24. Sugimoto T, Matsumoto T, Hosoi T, et al.: Three-year denosumab treatment in postmenopausal Japanese women and men with osteoporosis: results from a 1-year open-label extension of the Denosumab Fracture Intervention Randomized Placebo Controlled Trial (DIRECT). Osteoporos Int. 2015, 26:765-74.

10.1007/s00198-014-2964-2 